\title{
Concentrações de nitrogênio na dieta, no sangue e no leite de vacas lactantes no período pós-parto*
}

\author{
Carlos de Sousa Lucci ${ }^{1}$, Edison Valvasori ${ }^{2}$, Kleber Peixoto Junior ${ }^{1}$, Valter Fontolan ${ }^{1}$ \\ * Fundação de Amparo à Pesquisa do Estado de São Paulo - processo número 2000/01824-7 \\ 1 Universidade de Santo Amaro, São Paulo. \\ 2 Instituto de Zootecnia, Agência Paulista de Tecnologia dos Agronegócios.
}

\begin{abstract}
RESUMO - Foram utilizadas 24 vacas leiteiras em um delineamento em blocos casualizados com o objetivo de comparar três tratamentos compostos por dietas isoenergéticas, distintas quanto aos teores de proteína bruta $(\mathrm{PB})$ : $\mathrm{P} 100=100 \%$, $\mathrm{P} 130=133 \%$ e P166 = 166\% das exigências descritas pelo NRC (1989). Os acréscimos de PB foram obtidos como equivalentes protéicos mediante adição de uréia pecuária. Semanalmente, coletaram-se amostras dos alimentos, do leite e do sangue dos animais, desde os 30 dias anteriores até os 60 posteriores ao parto. As produções de leite e o peso das vacas foram registrados semanalmente. As concentrações de nitrogênio uréico foram determinadas nas amostras de leite (NUL) e de plasma (NUP). As produções médias de leite, por vaca e por dia, foram iguais a 12,4; 13,3; e 13,4 kg nos tratamentos P100, P133 e P166, respectivamente, aumentando de forma linear com o emprego de maiores quantidades de equivalente protéico nas rações. As concentrações de NUP e NUL, em mg/dL, aumentaram linearmente com o incremento de equivalente protéico nas dietas, segundo as equações $\hat{\mathrm{Y}}=16,83+0,202 \mathrm{X}$ e $\hat{\mathrm{Y}}=13,73+0,219 \mathrm{X}$, respectivamente. A correlação entre valores de NUP e NUL foi significativa, indicando que tanto os valores de NUP quanto os de NUL podem servir como indicadores das quantidades dietéticas de proteína degradável no rúmen, em vacas lactantes, e que valores mais elevados de equivalente em PB resultam em maiores produções de leite.
\end{abstract}

Palavras-chave: nitrogênio uréico no leite, nitrogênio uréico no plasma, produção de leite, proteína dietética

\section{Effects of different dietary crude protein levels on plasma and milk urea nitrogen on post calving lactating dairy cows}

\begin{abstract}
Twenty-four lactating dairy cows were assigned to a completely randomized block design to compare the effects of isoenergetic diets but different crude protein (CP) levels: P100- 100\%, P133- 133\% or P166- 166\% of the NRC (1989) requirements on the concentrations of urea nitrogen in plasma (PUN) and milk (MUN). Increasing levels of CP were obtained by adding urea to the diet. Feeds, milk, and blood were all collected weekly from 30 days before to 60 days after parturition. Milk yield and body weigh were also registered weekly in this trial. Milk yield averaged 12.4, 13.3, and 13.4 kg/d, respectively, on P100, P133, and P166 treatments and increased linearly with the incremental levels of urea in the diet. Concentrations of PUN and MUN also increased linearly when rumen-degradable protein (RDP) was increased in the diet resulting, respectively, in the following equations: $\mathrm{Y}=16.83+0.202 \mathrm{X}$ and $\mathrm{Y}=13.73+0.219 \mathrm{X}$. A highly significant correlation coefficient $(\mathrm{r}=0.603)$ between PUN and MUN was observed in this study. It can be concluded that PUN and MUN are useful indicators of dietary RDP levels and that higher contents of dietary nitrogen improved milk yield.
\end{abstract}

Key Words: dietary protein, milk yield, milk urea nitrogen, plasma urea nitrogen

\section{Introdução}

No início da lactação, é comum criadores fornecerem níveis elevados de proteína na dieta das vacas leiteiras (Elrod \& Butler, 1993). Essa prática, aliada a resultados conflitantes de pesquisas sobre as quantidades de proteína necessárias para o período pós-parto (Claypool et al., 1980), demonstra a importância da boa avaliação do estado nutricional dessa categoria animal. De fato, a proteína dietética é um dos fatores que modificam a fertilidade de bovinos (Canfield et al., 1990), de modo que o excesso da fração proteína degradável no rúmen (PDR) pode ser prejudicial à fertilidade (Elrod \& Butler, 1993). Resultados na literatura indicam que incrementos na ingestão de PDR aumentam as concentrações de amônia no rúmen e de uréia no sangue (Gustafsson \& Palmquist, 1993) e no leite (Oltner \& Wiktorsson, 1983).

A avaliação da quantidade de nitrogênio dietético realmente aproveitada pela vaca é um problema comum da prática criatória e poderia ser feita a partir das concentrações de $\mathrm{N}$ uréico no sangue. Este metabólito poderia gerar 
informações tanto do metabolismo protéico como energético por apresentar rápida difusão tissular e permitir sua análise no plasma sangüíneo (Eicher et al., 1999) e no leite (Peixoto Jr., 2003). As concentrações de $\mathrm{N}$ uréico em ambos os líquidos (plasma e leite) têm mostrado elevada correlação, conforme reportado por Oltner \& Wiktorsson (1983), Gustafsson \& Palmquist (1993), Ferguson (1997) e Baker et al (1995). Claypool et al. (1980) concluíram que o nitrogênio uréico do plasma (NUP) está diretamente associado à ingestão de proteína bruta (PB) da dieta. Howard et al. (1987), no entanto, observaram maiores valores de NUP com o fornecimento de proteínas de elevada degradabilidade. Moore \& Varga (1996) concluíram que o NUP pode ser um bom indicador da proteína não utilizada pelo animal e Hoff et al. (1997) indicaram correlação entre nitrogênio uréico do leite (NUL) e perda total de $\mathrm{N}$ igual a $\mathrm{r}=0,96$. Outros autores, como Frank \& Swensson (2002), Roseler et al. (1993) e Hinders (1996), têm demonstrado relação estreita entre proteína da dieta e nível de NUL.

Baker et al (1995) constataram que as concentrações de nitrogênio uréico do sangue (NUS) e do leite (NUL) tiveram elevada correlação $(r=0,96)$ e que $93 \%$ da variação de NUL foi determinada pela variação de NUS. Portanto, o uso do NUL tornou-se importante recurso para os nutricionistas com finalidade de avaliar a eficiência da utilização de proteína em várias dietas (Hinders, 1996).

A relação ingestão de proteína dietética x produção de leite tem apresentado resultados diversos. Bruckental et al. (1986) registraram incremento na produção de leite, apenas nos primeiros 60 dias pós-parto, à medida que aumentaram a quantidade de proteína da dieta, sugerindo que a produção obtida no início da lactação é mais sensível ao efeito da PB. Melhores produções resultantes de valores elevados de proteína dietética poderiam ocorrer pela disponibilidade de aminoácidos para síntese de proteína do leite, pela disponibilidade de energia por deaminação de aminoácidos ou por fatores como maior eficiência de utilização dos nutrientes absorvidos e incremento na ingestão de matéria seca (Macleod et al., 1984; Oldham, 1984). Entretanto, segundo Chalupa (1984), há um padrão de rendimentos decrescentes, no qual as respostas em produção de leite a quantidades progressivamente mais altas de proteína eventualmente se tornam menores. Outros autores relataram influência negativa de níveis mais altos de proteína dietética sobre a produção de leite. Excessos de PB na dieta foram relacionados a menores produções de leite, a altos níveis de NUL e a maior custo de alimentação (Arias \& Alonso, 1997). Finalmente, outros autores, como Santos et al. (2001) e Baker et al. (1995), não encontraram alterações nas produ- ções de leite de vacas alimentadas com maiores quantidades de PB, durante o pós-parto. Ressalta-se que quantidades reduzidas de proteína, $20 \%$ abaixo do recomendado pelo NRC (1989), são responsáveis por menores concentrações de NUS em vacas secas nos 60 dias pré-parto (Chew et al., 1984).

O aumento da ingestão de $\mathrm{PB}$ e a alteração na proporção entre as frações degradável e não-degradável no rúmen influenciam o grau e a duração do balanço energético negativo (BEN) após o parto, o que pode ser atribuído, entre outros fatores, a concentrações elevadas de amônia ruminal e, conseqüentemente, ao maior gasto de energia para as células hepáticas converterem em uréia o aporte excessivo de amônia (Oldham, 1984). Tanto as quantidades de NUS como as de NUL são derivadas da amônia absorvida através da parede ruminal e convertida em uréia no fígado (Ferguson et al., 1988).

Reduções nas taxas de fertilidade em vacas leiteiras recebendo excesso de proteína na dieta tem sido associadas a concentrações de NUP superiores a $19 \mathrm{mg} / \mathrm{dL}$ (Ferguson et al., 1993; Butler et al., 1996).

Os objetivos com este trabalho foram estabelecer curvas de regressão entre níveis progressivamente mais elevados de ingestão de nitrogênio e as concentrações resultantes de $\mathrm{N}$ uréico no soro sanguíneo e no leite, bem como mensurar a correlação entre valores de nitrogênio uréico no soro e no leite em dietas com a mesma quantidade de energia.

\section{Material e Métodos}

Vinte e quatro vacas mestiças tipo Mantiqueira, multíparas, com idades entre 5 e 7 anos e escore corporal de aproximadamente 3,5 em uma escala de 1 a 5 , foram escolhidas entre aquelas com partos previstos para março e abril de 2001. O experimento foi realizado no período de janeiro a maio, estação chuvosa no Brasil Central. As fêmeas de todos os tratamentos permaneceram sempre na mesma pastagem, formada de capim Panicum maximum, calculando-se, a partir do peso vivo dos animais, dos resultados preliminares de teores de MS e PB do capim, e das estimativas de consumo de MS (NRC,1989), ingestão aproximada de 0,6 a $0,7 \mathrm{~kg}$ de $\mathrm{PB} / \mathrm{animal} / \mathrm{dia}$ proveniente da pastagem. As vacas foram submetidas, pelo menos 40 dias antes da data prevista para o parto, a dietas contendo pastagem como único volumoso mais diferentes quantidades de equivalentes protéicos nas misturas de alimentos concentrados avaliando-se ingestões totais de 100, 133 e 166\% das exigências em PB (NRC, 1989), respectivamente, para os trata- 
mentos P100, P133 e P166. Os acréscimos de PB foram obtidos mediante adição de quantidades de equivalentes em proteína degradável no rúmen (PDR) na forma de uréia pecuária $(42 \% \mathrm{~N})$. Manteve-se, em todos os tratamentos, a mesma quantidade de energia, com o objetivo de provocar, pela ação dos tratamentos B e C, aumento das concentrações de nitrogênio amoniacal no conteúdo ruminal, sem possibilidade de plena formação de proteína microbiana.

Durante o período experimental (quatro semanas anteriores a oito posteriores ao parto), coletaram-se semanalmente amostras dos alimentos, do leite e do sangue dos animais e registraram-se as produções de leite e os pesos das vacas. As concentrações de nitrogênio uréico foram determinadas nas amostras de leite (NUL) e de plasma (NUP). As amostras de alimentos foram submetidas a análise dos teores de MS e PB, conforme AOAC (1980), e as de leite, coletadas nas ordenhas vespertinas (15h30), foram mantidas congeladas, sendo submetidas à centrifugação a $4.000 \mathrm{rpm}$ por 20 minutos, separando-se a gordura por aspiração. Em seguida, as amostras de leite foram adicionadas de cinco gotas de ácido acético e novamente centrifugadas para retirada da proteína, dando origem ao lactosoro isento de proteínas e de gordura. Neste material, estimou-se a concentração de NUL, utilizando-se o kit Sigma (urea nitrogen procedure), Sigma Diagnósticos, St. Louis, MO, conforme recomendado por Roseler et al. (1993), Baker et al. (1995) e Butler et al. (1996). As pesagens foram feitas semanalmente, sempre pela manhã, após jejum prévio de água e alimentos por 10 horas. Nessas ocasiões, foram coletadas amostras de sangue, imediatamente centrifugadas a $4.000 \mathrm{rpm}$ por 20 minutos, separando-se plasma e hemácias. O plasma foi mantido congelado até o processamento. Para determinação do NUP, foram empregados kits da LABtest diagnostica, segundo procedimentos descritos por Peixoto (2003). Visando padronizar os efeitos do tempo decorrido após as refeições e considerando-se a facilidade de obtenção dessas amostras durante a contenção das vacas, provocando o mínimo de distúrbio aos animais, coletaram-se as amostras de sangue sempre após 10 horas de jejum, na ocasião das pesagens.

As vacas permaneceram na mesma pastagem e duas vezes ao dia eram conduzidas a um estábulo anexo, onde recebiam, independentemente do tratamento, $3,0 \mathrm{~kg}$ de mistura concentra$\mathrm{da} / \mathrm{animal} / \mathrm{dia}$, em duas refeições de $1,5 \mathrm{~kg}$, às $8 \mathrm{e} 16 \mathrm{~h}$ (Tabela 1 ). Para se enquadrarem nos tratamentos descritos, as fêmeas do tratamento $\mathrm{B}$ recebiam mais $57 \mathrm{~g}$ de uréia e as do tratamento $\mathrm{C}$, mais $114 \mathrm{~g}$ de uréia, com as quantidades de nitrogênio nãoprotéico divididas igualmente entre as duas porções diárias de concentrado. Dessa maneira, os valores individuais por dia de equivalentes protéicos provenientes dos concentrados foram de 450, 600 e $750 \mathrm{~g}$ PB, para as fêmeas nos tratamentos P100, P133 e P166, respectivamente.

À medida em que as fêmeas pariam, permaneceiam junto com as outras do rebanho durante o momento das ordenhas, realizadas duas vezes ao dia, às $6 \mathrm{~h} 30$ e $15 \mathrm{~h} 30$. Depois das ordenhas, eram conduzidas ao estábulo experimental anexo, reunindo-se às vacas ainda gestantes, mas recebendo como diferencial $3,0 \mathrm{~kg}$ da mistura concentrada destinada às fêmeas em lactação (Tabela 1). As vacas do tratamento B receberam mais $72 \mathrm{~g}$ de uréia e as do tratamento $\mathrm{C}, 144 \mathrm{~g}$ de uréia/animal/dia, de modo que, para produções em torno de $12 \mathrm{~kg}$ de leite/dia, as quantidades ingeridas de PB (como equivalente protéico) pelos concentrados fossem iguais a 690, 892 e $1094 \mathrm{~g}$, respectivamente, para os tratamentos P100, P133 e P166. Assim, as fêmeas secas e lactantes receberam 33 e $66 \%$ a mais de equivalente protéico em comparação às do tratamento controle (P100). No caso das vacas lactantes, foi adicionado aos 3,0 kg diários de mistura concentrada mais $1 \mathrm{~kg}$ para cada $3,0 \mathrm{~kg}$ de leite produzido acima dos $12 \mathrm{~kg}$ diários, ajustando-se essas quantidades quinzenalmente pela variação média de todos os tratamentos.

A composição das misturas bases empregadas em todos os tratamentos constam na Tabela 1, para as situações vacas secas e prenhes ou vacas lactantes e vazias.

O experimento de campo foi conduzido na Estação Experimental de Produção Animal de Pindamonhangaba, órgão do Instituto de Zootecnia da Secretaria de Agricultura do estado de São Paulo, e as análises, no Laboratório de Nutrição Animal da Universidade de Santo Amaro, UNISA, em São Paulo.

O delineamento estatístico foi em blocos ao acaso formando-se quatro blocos de seis animais, com repetição de tratamentos dentro de blocos, adotando-se como significativo o nível de probabilidade $\mathrm{P}=0,05$.

Tabela 1 - Composição das misturas concentradas (\%) utilizadas nos tratamentos Table 1 - Concentrate composition for all treatments

\begin{tabular}{lcccccc}
\hline $\begin{array}{l}\text { Vacas } \\
\text { Cows }\end{array}$ & $\begin{array}{c}\text { Farelo soja } \\
\text { Soybean meal }\end{array}$ & $\begin{array}{c}\text { Milho } \\
\text { Corn }\end{array}$ & $\begin{array}{c}\text { Sal } \\
\text { Salt }\end{array}$ & $\begin{array}{c}\text { PB } \\
C P\end{array}$ & $\begin{array}{c}\text { PDR } \\
\text { RDP }\end{array}$ & $\begin{array}{c}\text { PDR/PB } \\
\text { RDP/CP }\end{array}$ \\
\hline $\begin{array}{l}\text { Secas } \\
\text { Dry }\end{array}$ & 19 & 79 & 2 & 15,0 & 9,7 & 64,5 \\
Lactantes & 41 & 57 & 2 & 23,4 & 15,2 & 64,9 \\
Lactating & & & & & \\
\hline
\end{tabular}


Os resultados foram analisados pelo programa computacional Statistical Analysis System (SAS, 1985). Anteriormente, foi verificada a normalidade dos resíduos comparando-se a homogeneidade das variâncias pelo teste qui-quadrado. Para avaliar os efeitos dos tratamentos sobre a produção de leite, NUP e NUL, nos períodos pré e pósparto, os dados foram submetidos à análise de regressão. Como não houve interação tempo x tratamento, realizou-se análise de variância para avaliar a concentração de NUP e NUL durante as oito semanas pós-parto, comparando-se as médias pelo teste Tukey (Pimentel Gomes, 1985).

\section{Resultados e Discussão}

Na Tabela 2 constam as médias dos pesos obtidos, em $\mathrm{kg} / \mathrm{animal}$, nos diferentes tratamentos. Foram considerados os resultados de pesagens semanais realizadas dos 30 dias anteriores aos 60 posteriores ao parto.

Tanto nos pesos obtidos antes como após o parto (Tabela 2), não foram encontradas regressões significativas entre porções mais elevadas de equivalentes protéicos nas dietas e nos pesos vivos dos animais. Este resultado confirma aqueles registrados por Howard et al. (1987) e Santos et al. (2001), que observaram que o escore de condição corporal (ECC) médio nos períodos pré e pósparto não foi influenciado pelos níveis de proteína da dieta e sugeriram que o aumento da densidade protéica no préparto não tem impacto na perda de reservas corporais durante as últimas quatro semanas de gestação e nas primeiras 21 semanas pós-parto.

A média geral dos pesos das vacas, considerando todos os tratamentos, foi igual a $539,6 \mathrm{~kg}$ antes e a $489,7 \mathrm{~kg}$ após o parto $(\mathrm{P}<0,01)$, o que equivaleu a variações de peso/ semana/animal iguais a $7,07 \mathrm{~kg}$ antes e $-6,41 \mathrm{~kg}$ após o parto

Tabela 2 - Médias individuais dos pesos vivos no pré-parto, pós-parto e no total do período experimental (pré e pós-parto)

Table 2 - Means of pre-calving, post-calving, and pre plus post-calving body weights for treatments

\begin{tabular}{lccc}
\hline $\begin{array}{l}\text { Tratamento } \\
\text { Treatment }\end{array}$ & $\begin{array}{c}\text { Peso } \\
\text { pré-parto } \\
\text { Pre-calving } \\
\text { weight }\end{array}$ & $\begin{array}{c}\text { Peso } \\
\text { pós-parto } \\
\text { Post-calving } \\
\text { weight }\end{array}$ & $\begin{array}{c}\text { Peso } \\
\text { pré+pós } \\
\text { Pre }+ \text { post- } \\
\text { calving weight }\end{array}$ \\
\hline & & $\mathrm{kg}$ & \\
\hline P-100 & 529,38 & 489,59 & 510,1 \\
P-130 & 541,44 & 496,20 & 519,2 \\
P-160 & 546,50 & 485,39 & 514,5 \\
Média & $539,62^{\text {a }}$ & $489,72^{\mathrm{b}}$ & \\
Mean & & &
\end{tabular}

Letras diferentes na mesma coluna indicam diferença significativa entre números $(\mathrm{P}<0,05)$.

Different letters in same colunn means significantly different values $(P<0.05)$.
$(\mathrm{P}<0,01)$, coerentes com o balanço energético negativo normal ao período seguinte à parição. As concentrações de NUP, considerando as médias de todos os tratamentos, foram estatisticamente diferentes $(\mathrm{P}<0,001)$ entre os períodos pré $(15,60 \mathrm{mg} / \mathrm{dL})$ e pós-parto $(20,19 \mathrm{mg} / \mathrm{dL})$, provavelmente em razão da alimentação mais rica em proteína fornecida no início da lactação, em todos os tratamentos.

Na Tabela 3 são descritas a produção de leite, em $\mathrm{kg} / \mathrm{vaca} / \mathrm{dia}$, e as concentrações de NUP (mg/dL) e NUL $(\mathrm{mg} / \mathrm{dL})$ nos 30 dias anteriores e nos 60 posteriores ao parto, nos diferentes tratamentos.

Observou-se aumento linear na produção de leite com o incremento dos teores de equivalentes protéicos nos diversos tratamentos, conforme a equação de regressão $\hat{\mathrm{Y}}=12,14+0,048 \mathrm{X}$. Os resultados foram semelhantes aos obtidos por Bruckental et al. (1986), mas esses autores ressaltaram o fato de a melhoria em desempenho ter sido registrada apenas nos primeiros 60 dias de lactação. Oldham (1984) também constatou aumentos na produção de leite com maiores ingestões de proteína dietética e atribuiu os resultados à disponibilidade de aminoácidos para síntese de proteína do leite e à disponibilidade de energia pela deaminação dos aminoácidos. Contudo, neste experimento, o aumento de nitrogênio decorreu da administração de uréia, excluindo-se a contribuição energética por meio de aminoácidos. Embora a fração de proteína microbiana resultante do nitrogênio não-protéico deva ser considerada responsável pelas maiores produções de leite, os níveis crescentes de uréia plasmática (Tabela 3) sugerem maior absorção de amônia pela parede ruminal, uma vez que o excedente de NNP fornecido aos animais não foi assimilado pelas bactérias ruminais. Também neste estudo, as produções de leite, obtidas em quantidades cada vez menores de P100 para P133 e P166, poderiam enquadrar-se em um padrão de rendimentos decrescentes, no qual incrementos equivalentes em PB (equivalente protéico) correspondem a aumentos cada vez menores na produção de leite, conforme descrito por Chalupa (1984). Outros autores, como Santos et al. (2001) e Baker et al. (1995), contrariando esse dados, não encontraram alterações nas produções leiteiras, ao empregarem elevados níveis de proteína na dieta.

As relações entre ingestões de proteína dietética e valores de NUP e NUL têm sido colocadas como fator de confiança no emprego destes patâmetros como indicadores do estado nutricional protéico das vacas de leite. Ressaltam-se os aumentos lineares nas concentrações de NUP durante o período pré-parto $(\mathrm{P}<0,01 ; \hat{\mathrm{Y}}=12,54+0,210$ $\mathrm{X}$ ), como no período referente ao pós-parto $(\mathrm{P}<0,01$; $\hat{\mathrm{Y}}=16,83+0,202 \mathrm{X})$ (Tabela 3 ). Neste experimento, as 
Tabela 3 - Médias de concentrações de NUP (mg/dL) nos períodos pré e pós-parto e concentrações de NUL (mg/dL) no pós-parto. Produções médias de leite ( $\mathrm{kg} / \mathrm{vaca} / \mathrm{dia})$ do parto aos 60 dias pós-parto

Table 3- $\quad$ Pre and post-calving plasma urea nitrogen concentrations $(P U N)(\mathrm{mg} / \mathrm{dL})$, post-calving milk urea nitrogen concentrations $(\mathrm{MUN})(\mathrm{mg} / \mathrm{dL})$, and milk yield $(\mathrm{kg} / \mathrm{cow} / \mathrm{day})$ from calving to 60 days aftercalving

\begin{tabular}{|c|c|c|c|c|}
\hline $\begin{array}{l}\text { Tratamento } \\
\text { Treatment }\end{array}$ & $\begin{array}{l}\text { NUP-pré } \\
\text { PUN, pre }\end{array}$ & $\begin{array}{l}\text { NUP-pós } \\
\text { PUN, post }\end{array}$ & $\begin{array}{l}\text { NUL } \\
\text { MUN }\end{array}$ & $\begin{array}{c}\text { Leite }(\mathrm{kg}) \\
\quad \text { Milk }\end{array}$ \\
\hline P- 100 & 12,78 & 16,79 & 14,15 & 12,4 \\
\hline P -13 & 15,23 & 19,96 & 16,50 & 13,3 \\
\hline P-166 & 19,11 & 22,87 & 20,71 & 13,4 \\
\hline Reg linear & $(\mathrm{P}<0,01)$ & $(\mathrm{P}<0,01)$ & $(\mathrm{P}<0,01)$ & $(\mathrm{P}<0,05)$ \\
\hline \multicolumn{5}{|c|}{ Linear regression } \\
\hline $\mathrm{a}$ & 12,540 & 16,830 & 13,720 & 12,140 \\
\hline $\mathrm{b}$ & 0,210 & 0,202 & 0,219 & 0,048 \\
\hline
\end{tabular}

Dados submetidos à analise de regressão $(\mathrm{Y}=\mathrm{a}+\mathrm{bx})$.

Data submitted to regression analysis $(Y=a+b x)$.

ingestões de maiores quantidades de equivalentes em proteína degradável no rúmen resultaram em aumentos nas concentrações plasmáticas de nitrogênio uréico, presumindo-se que esses valores decorreram do aumento de nitrogênio amoniacal do conteúdo ruminal nas fêmeas que receberam maiores níveis de uréia na alimentação. Do mesmo modo que neste trabalho, Claypool et al. (1980) concluíram que o NUP foi estreita e diretamente associado à ingestão de PB da dieta. No entanto, Howard et al. (1987) observaram maiores valores de NUP com o fornecimento de proteínas de elevada degradabilidade, o que merece atenção considerados os resultados deste estudo, visto que a administração de equivalente protéico ocorreu por administração de uréia. Moore \& Varga (1996) concluíram que o NUP pode ser bom indicador da proteína não utilizada pelo animal, o que está de acordo com os resultados deste trabalho, pois o nitrogênio excedente na dieta, fornecido na forma não-protéica, não foi acompanhado por acréscimo correspondente de energia e provocou aumento significativo nas concentrações de NUP.

Também deve-se considerar que a aplicação de tratamentos com maiores níveis de equivalentes protéicos nas rações (Tabela 3 ) resultou em aumento linear das concentrações de NUL $(\mathrm{P}<0,01 ; \hat{\mathrm{Y}}=13,73+0,219 \mathrm{X})$. Hof et al. (1997) indicaram correlação entre o NUL e a eficiência de utilização da proteína pela vaca, de modo que a concentração média de NUL esteve significativamente correlacionada aos valores médios de perda total de $\mathrm{N}(\mathrm{r}=0,96)$. De acordo com os autores, a ingestão de proteína degradável no rúmen foi responsável por $81 \%$ da variação do NUL, o que pode ter reforçado as respostas aos tratamentos aplicados neste experimento. Corroborando os resultados deste estudo, Frank \& Swensson (2002) observaram maiores valores de NUL em animais alimentados com níveis superiores de PB e Roseler et al. (1993) concluíram que variar a porcentagem de PDR e PNDR na dieta afeta significativamente o NUL.
De fato, à medida que se elevaram os níveis de NUP conforme aplicados os tratamentos, também foram aumentados os níveis de NUL, obtendo-se a correlação de 0,60376 $(\mathrm{P}<0,01)$, que permite afirmar que concentrações de NUL, assim como as de NUP, são bons indicadores dos teores de nitrogênio empregados na alimentação ou, pelo menos, em termos de nitrogênio como equivalente em PDR na alimentação, como registraram Baker et al. (1995), Eicher et al. (1999), Peixoto Jr. (2003), Oltner \& Wiktorsson (1983), Gustafsson \& Palmquist (1993) e Ferguson (1997).

O uso de NUL como indicador é de fácil aplicação prática, pois permite a obtenção de amostras do tanque de coleta, em nível de rebanho (Peixoto Jr., 2003), tornando-se valiosa forma de os nutricionistas avaliarem a eficiência da utilização de proteína em várias dietas (Hinders, 1996).

Consta na Tabela 4 a evolução das concentrações de NUP e NUL nas semanas seguintes ao parto, independentemente do tratamento fornecido. Observa-se que as concentrações de NUP e de NUL aumentaram com o transcorrer das semanas pós-parto, o que pode ser atribuído aos maiores teores de PB das rações ingeridas tão $\log 0$ iniciaram as lactações.

\section{Conclusões}

Quantidades de equivalentes protéicos superiores às recomendadas por tabelas de exigências nutricionais em dietas para vacas no início da lactação causam incrementos da produção de leite e elevação das concentrações de nitrogênio uréico do plasma e do leite.

Considerando correlação entre as concentrações de nitrogênio uréico do plasma e do leite, sugere-se o emprego de qualquer uma dessas variáveis (NUP e NUL) como parâmetro de avaliação do teor protéico em dietas de vacas lactantes. 
Tabela 4 - Concentrações de nitrogênio ureíco do leite (NUL) e de nitrogênio uréico do plasma (NUP) nas semanas seguintes ao parto

Table 4 - Post-calving weekly concentrations of milk urea nitrogen $(M U N)$ and plasma urea nitrogen (PUN)

\begin{tabular}{lcc}
\hline $\begin{array}{l}\text { Semanas pós-parto } \\
\text { Weeks after calving }\end{array}$ & NUP & NUL \\
PUN & $M U N$ \\
\hline 1 & $14,48^{\mathrm{a}}$ & $14,31 \mathrm{a}$ \\
2 & $14,74^{\mathrm{a}}$ & $14,29 \mathrm{a}$ \\
3 & $15,10^{\mathrm{a}}$ & $14,75 \mathrm{a}$ \\
4 & $16,93 \mathrm{ac}$ & $16,93 \mathrm{~b}$ \\
5 & $17,89 \mathrm{bc}$ & $17,65 \mathrm{bc}$ \\
6 & $19,96 \mathrm{bd}$ & $19,66 \mathrm{~cd}$ \\
7 & $19,01 \mathrm{~cd}$ & $18,77 \mathrm{bc}$ \\
8 & $21,29 \mathrm{~d}$ & $21,49 \mathrm{~d}$ \\
\hline
\end{tabular}

Letras diferentes na mesma coluna indicam diferença significativa $(P<0,05)$. Different letters in the same column differ $(P<0.05)$ significantly.

\section{Literatura Citada}

ASSOCIATION OF OFFICIAL ANALITICAL CHEMISTS - AOAC. Official methods of analysis. 10.ed. Washington D.C.: 1980. $1051 \mathrm{p}$.

ARIAS, J.; ALONSO, A.N. Importância dos níveis de nitrogênio uréico no leite e no sangue de vacas leiteiras. Latin América Animal Science Meeting, p.73-84, 1997.

BAKER, L.D.; FERGUSON, J.D.; CHALUPA, W. Responses in urea and true protein of milk to different protein feeding schemes for dairy cows. Journal of Dairy Science, v.78, p.2424-2434, 1995 .

BRUCKENTAL, I.; TAGARI, H.; AMIR, S. et al. The effect on the performance of dairy cattle of plant protein concentration and of urea or urea phosphate supplementation in the diet. Animal Production, v.43, p.73-82, 1986

BUTLER, W.R.; CALAMAN, J.J.; BEAM, S.W. Plasma and milk urea nitrogen in relation to pregnancy rate in lactating dairy cattle. Journal of Animal Science, v.74, p.858-65, 1996.

CANFIELD, R.W.; SNIFFEN, C.J.; BUTLER, W.R. Effects of excess degradable protein on postpartum reproduction and energy balance in dairy cattle. Journal of Dairy Science, v.73, p.2342-2349, 1990.

CHALUPA, W. Discussion of protein symposium. Journal of Dairy Science, v.67, p.1134-1152, 1984.

CHEW, B.P.; MURDOCK, F.R.; RILEY, E.E. et al. Influence of prepartum dietary crude protein on growth hormone, insulin, reproduction, and lactation of dairy cows. Journal of Dairy Science, v. 67, p. $270-275,1984$.

CLAYPOOL, D.W.; PANGBORN, M.C.; ADAMS, H.P. Effects of dietary on high-producing dairy cows in early lactation. Journal of Dairy Science, v.63, p.6833-837, 1980.

EICHER, R.; BOUCHARD, E.; BIGRAS-POULIN, M. Factors affecting milk urea nitrogen and protein concentrations in Quebec dairy cows. Preventive Veterinary Medicine, v.39, p.53-63, 1999 .

ELROD, C.C.; BUTLER, W.R. The relatioship between blood and fertility parameters in post partum dairy cows. Journal of Animal Science, v.71, p.694-701, 1993.
FERGUSON, J.D. [About MUN. Documento eletrônico publicado em 1997 na internet]. Disponível em http://www.dhiqa.psu.edu/ mun.htm.

FERGUSON, J.D.; GALLIGAN, D.T.; BLANCHARD, T. et al Serum urea nitrogen and conception rate: The usefulness of test information. Journal of Dairy Science, v.76, p.3742-3746, 1993.

FERGUSON, J.D.; BLANNCHARD, T.; GALLIGAN, D.T. et al Infertility in dairy cattle fed a high percentage of protein degradable in the rumen. Journal of Animal Veterinary Medical Association, v. 192, p.659-662, 1988.

FRANK B.; SWENSSON, C. Relationship between content of crude protein in rations for dairy cows and milk productions, concentration of urea in milk and ammonia emissions. Journal of Dairy Science, v. 85, p.1829-1838, 2002.

GUSTAFSSON, A.H.; PALMQUIST, D.L. Diurnal variation of rumen ammonia, serum urea, and milk urea in dairy cows at high and low yields. Journal of Dairy Science, v.76, p.475-484, 1993.

HINDERS, R. MUN Indicates adequacy of protein, carbohydrates in milking cow rations. Feedstuffs, p.11, 1996.

HOF, G.; VERVOORN, M.D.; LENAERS, P.J. et al. Milk urea nitrogen as a tool to monitor the protein nutrition of dairy cows. Journal of Dairy Science, v.80, p.3333-40, 1997.

HOWARD H.J.; ALSETH, E.P.; ADAMS, G.D. et al Influence of dietary protein on reproductive performance of dairy cows. Journal of Dairy Science, v.70 p.1563-1571, 1987.

MACLEOD, G.K.; GRIEVE, D.G.; McMILLAN, I. et al. Effect of varying protein and energy densities in complete rations fed to cows in first lactation. Journal of Dairy Science, v.67, p.1421-1429, 1984.

MOORE D.A; VARGA, G. BUN and MUN: Urea nitrogen testing in dairy cattle. Compendium on Continual Education for the Practicing Veterinary, v.18, p.712-720, 1996.

NATIONAL RESEARCH COUNCIL - NRC. Nutrient requirements of dairy cattle. Washington, D.C: National Academy of Science, National Academy Press, 1989. 157p.

OLDHAM, J.D. Protein - energy relationships in dairy cows. Journal of Dairy Science, v.67, p.1090-1114, 1984.

OLTNER, R.; WIKTORSSON, H. Urea concentration in milk and blood as influenced by feeding varying amounts of protein and energy to dairy cows. Livestock Production Science, v.10, p.457-467, 1983.

PEIXOTO JR., K.C. Nitrogênio uréico do leite como indicador de desempenho reprodutivo de rebanhos leiteiros. São Paulo, 2003.89p. Tese (doutorado) - Faculdade de Medicina Veterinária e Zootecnia, Universidade de São Paulo.

PIMENTEL GOMES, F. Curso de estatística experimental. Piracicaba: Escola Superior de Agricultura Luiz de Queiroz, 1985. $467 \mathrm{p}$.

ROSELER, D.K.; FERGUSON, J.D.; SNIFFEN, C.J. et al Dietary protein degradability effects on plasma and milk urea nitrogen and milk no protein nitrogen in Holstein cows. Journal of Dairy Science, v.76, p.525-534, 1993.

SANTOS, J.E.P.; DePETERS, E.J.; JARDON, P.W. et al Effect of prepartum dietary protein level on performance of primigravid and multiparous Holstein dairy cows. Journal of Dairy Science, v.84, p.213-224, 2001.

STATISTICAL ANALYSES SYSTEM - SAS. User's guide: statistics. 5.ed. Cary: 1985.

Recebido: 29/03/04 Aprovado: 13/09/05 